\title{
A simple method for assessing intestinal inflammation in Crohn's disease
}

J Tibble, K Teahon, B Thjodleifsson, A Roseth, G Sigthorsson, S Bridger, R Foster, R Sherwood, M Fagerhol, I Bjarnason

Department of Medicine, Guy's, King's, St Thomas' Medical School, London, UK J Tibble

G Sigthorsson

$S$ Bridger

R Foster

R Sherwood

I Bjarnason

Department of Gastroenterology, Nottingham City Hospital, Nottingham, UK

K Teahon

Department of Medicine, Iceland University Hospital, Reykjavik, Iceland

B Thjodleifsson

Department of Medicine, Aker University Hospital, Oslo, Norway

A Roseth

Department of Immunology and Transfusion, Ullevaal University Hospital, Oslo, Norway, and Aker University Hospital, Oslo, Norway M Fagerhol

Correspondence to: Professor I Bjarnason, Department of Medicine, Guy's, King's, St Thomas's Medical School, Bessemer Road, London SE5 9PJ, UK. Email:

ingvar.bjarnason@kcl.ac.uk

Accepted for publication 4 April 2000

\begin{abstract}
Background and aims-Assessing the presence and degree of intestinal inflammation objectively, simply, and reliably is a significant problem in gastroenterology. We assessed faecal excretion of calprotectin, a stable neutrophil specific marker, as an index of intestinal inflammation and its potential use as a screening test to discriminate between patients with Crohn's disease and those with irritable bowel syndrome.
\end{abstract}

Methods-The validity of faecal calprotectin as a marker of intestinal inflammation was assessed in 22 patients with Crohn's disease (35 studies) by comparing faecal excretions and concentrations using four day faecal excretion of ${ }^{111}$ indium white cells. A cross sectional study assessed the sensitivity of faecal calprotectin concentration for the detection of established Crohn's disease $(n=116)$. A prospective study assessed the value of faecal calprotectin in discriminating between patients with Crohn's disease and irritable bowel syndrome in 220 patients referred to a gastroenterology clinic.

Results-Four day faecal excretion of ${ }^{111}$ indium (median $8.7 \%$; 95\% confidence interval (CI) $7-17 \%$; normal $<1.0 \%$ ) correlated significantly $(\mathrm{p}<0.0001)$ with daily (median ranged from 39 to $47 \mathrm{mg}$; normal $<3 \mathrm{mg} ; \boldsymbol{r}=0.76-0.82$ ) and four day faecal calprotectin excretion (median $101 \mathrm{mg}$; 95\% CI 45-168 mg; normal $<11 \mathrm{mg} ; r=0.80$ ) and single stool calprotectin concentrations (median $118 \mathrm{mg} / 1 ; 95 \%$ CI 36-175 $\mathrm{mg} / \mathbf{1}$; normal $<10 \mathrm{mg} / \mathbf{1} ; \boldsymbol{r}=0.70$ ) in patients with Crohn's disease. The cross sectional study showed a sensitivity of $96 \%$ for calprotectin in discriminating between normal subjects ( $2 \mathrm{mg} / 1 ; 95 \%$ CI $2-3 \mathrm{mg} / \mathrm{l}$ ) and those with Crohn's disease $(91 \mathrm{mg} / 1$; 95\% CI 59-105 mg/l). With a cut off point of $30 \mathrm{mg} / 1$ faecal calprotectin has $100 \%$ sensitivity and $97 \%$ specificity in discriminating between active Crohn's disease and irritable bowel syndrome.

Conclusion-The calprotectin method may be a useful adjuvant for discriminating between patients with Crohn's disease and irritable bowel syndrome.

(Gut 2000;47:506-513)

Keywords: inflammatory bowel disease; Crohn's disease; intestinal inflammation; irritable bowel syndrome
Ulcerative colitis and Crohn's disease are chronic inflammatory bowel disorders characterised clinically by periods of well being punctuated by episodes of clinical disease activity. The presence of disease in ulcerative colitis and assessment of disease activity is not a major problem and is amenable to sigmoidoscopic visualisation with direct histopathological biopsy examination as the disease is uniform and commences distally. This is not feasible in Crohn's disease because of its variable location and the patchy nature of the inflammation. Clinical $^{1-3}$ and laboratory (such as erythrocyte sedimentation rate (ESR), C reactive protein (CRP), $\alpha_{1}$ antitrypsin, neutrophil elastase, platelet counts ${ }^{4-7}$ ) disease activity scores were devised as possible yardsticks of severity for these patients. ${ }^{1}$ These are widely used and easily applied, ${ }^{1-3}$ but laboratory tests in particular are at best non-specific, being abnormal in various non-intestinal diseases. ${ }^{5}$

In an attempt to overcome some of these problems the technique of ${ }^{111}$ indium labelled neutrophils was modified for gastroenterological use. This involves abdominal scintigraphy and four day faecal collection, the latter providing a specific, quantitative, and sensitive measure of intestinal inflammation. ${ }^{8-12}$ Active Crohn's disease (and ulcerative colitis) is characterised by a 10-fold or more increased migration of neutrophils from the circulation to the diseased intestine. ${ }^{89}$ It was hoped that the technique could be used in the initial assessment of patients where the differential diagnosis is between Crohn's disease and the irritable bowel syndrome, a non-inflammatory bowel disease which represents a large part of gastroenterological practice. However, the main drawback of the technique for routine use is that it requires special sterile labelling facilities, is costly (about $£ 300 /$ patient), and involves radiation (8.5-17 millisieverts $(\mathrm{mSv})$ ) to a dose equivalent to or greater than a barium enema. Furthermore, there are practical problems with obtaining complete faecal collections over four days. For these reasons the use of the ${ }^{111}$ indium neutrophil technique has been limited to only a few research centres.

An alternative approach to assess the presence of intestinal inflammation ${ }^{13}$ is to analyse whole gut lavage fluid ${ }^{14}$ or better still quantitate protease resistant neutrophil derived proteins such as elastase ${ }^{15}$ or lactoferrin ${ }^{16}{ }^{17}$ in stool to maintain the non-invasiveness of the procedure. Calprotectin is one such protein. It is

Abbreviations used in this paper: ESR, erythrocyte sedimentation rate; CRP, $C$ reactive protein; CDAI, Crohn's disease activity index. 
largely confined to neutrophils where it accounts for more than $60 \%$ of cytosolic protein. ${ }^{18-20}$ It resists metabolic degradation by intestinal bacteria, being stable in stool for up to one week at room temperature. ${ }^{18}$ As it can be measured with ease in faeces it has the potential to be used in a routine screening procedure as an aid to discriminate between normal and inflamed intestines.

A previous study has shown a significant correlation between faecal calprotectin concentration and histological disease activity in colonic biopsies in patients with ulcerative colitis. ${ }^{20}$ The validity of faecal calprotectin as a marker of acute inflammation in patients with Crohn's disease, where the inflammation is patchy or inaccessible for biopsy sampling, is however unknown. Our studies had three main objectives: (i) to validate the calprotectin method as a surrogate marker of inflammation by comparing faecal excretion (and single stool concentrations) of calprotectin with faecal excretion of ${ }^{11}$ indium white cells in patients with Crohn's disease, (ii) to assess the sensitivity of the method for detecting established Crohn's disease in a cross sectional study, and (iii) to assess in a prospective fashion the sensitivity and specificity of the calprotectin technique in discriminating between normal and Crohn's disease in consecutive patients referred to a gastroenterology outpatient clinic for this purpose.

\section{Subjects and methods}

The studies were approved by the local ethics committees at the Iceland University Hospital, Nottingham City Hospital, and King's College Hospital, and were in three parts. The first part validated the calprotectin method by comparing faecal calprotectin excretions in milligrams (one and four days) with excretion of ${ }^{11}$ indium white cells over four days. However, for routine use it would be preferable to analyse single stool specimens rather than complete collections. Therefore, we also assessed the correlation between single stool calprotectin concentrations $(\mathrm{mg} / \mathrm{l})$ with ${ }^{111}$ indium faecal excretions. The second part assessed the sensitivity of single stool faecal calprotectin concentrations in the detection of patients with established Crohn's disease. The third part assessed the potential of single stool faecal calprotectins to distinguish between Crohn's disease and the irritable bowel syndrome in patients specifically referred to a gastroenterological outpatient clinic for this purpose.

COMPARISON OF FAECAL EXCRETION AND CONCENTRATION OF CALPROTECTIN WITH FOUR DAY FAECAL EXCRETION OF ${ }^{11}$ INDIUM WHITE CELLS

Twenty two patients with established Crohn's disease were studied on 35 occasions. They underwent ${ }^{111}$ indium labelling of white cells and individual stools were collected over four days. The four day faecal excretion of ${ }^{111}$ indium white cells (percentage of dose of the labelled cells) was correlated with daily and the total four day faecal excretion of calprotectin (mg) and with single stool calprotectin concentrations $(\mathrm{mg} / \mathrm{l})$ in the first morning stool sample on the second day of the study. This provided assessment of the day to day variation in calprotectin excretion as well as the variation in calprotectin concentrations in individual stool samples.

A diagnosis of Crohn's disease was made based on standard criteria ${ }^{21}$ from a combination of radiological, endoscopic, and histopathological investigations as well as the clinical history. The 22 patients (three of whom were studied twice at least six months apart) had active Crohn's disease (defined as a Harvey-Bradshaw score of 5 or more, which corresponds to a modified Crohn's disease activity index (CDAI) score of over $150,{ }^{22}{ }^{23}$ or a four point increase or more in the HarveyBradshaw disease activity index from baseline in patients that had undergone intestinal surger ${ }^{2}$ ) and 10 repeated the investigations while in clinical remission following treatment. Table 1 shows the demographic details and characteristics of these patients. Patients with serious coexisting cardiovascular, pulmonary, hepatic, renal, or musculoskeletal disease, severe immune deficiency, malignancy, misusing alcohol, or receiving non-steroidal antiinflammatory drugs were excluded from the

Table 1 Demographic details of patients

\begin{tabular}{|c|c|c|c|c|c|}
\hline \multirow[b]{2}{*}{ Characteristic } & \multirow[b]{2}{*}{$\begin{array}{l}\text { Comparative } \\
\text { study }\end{array}$} & \multirow[b]{2}{*}{$\begin{array}{l}\text { Cross sectional } \\
\text { study }\end{array}$} & \multicolumn{3}{|c|}{ Prospective study } \\
\hline & & & $\begin{array}{l}\text { Crohn's } \\
\text { disease }\end{array}$ & $\begin{array}{l}\text { Irritable bowel } \\
\text { syndrome }\end{array}$ & $\begin{array}{l}\text { Miscellaneous } \\
\text { diagnosis }\end{array}$ \\
\hline$n$ & 22 & 112 & 31 & 159 & 30 \\
\hline $\operatorname{Sex}(M / F)$ & $12 / 10$ & $62 / 50$ & $13 / 18$ & $38 / 121$ & $12 / 18$ \\
\hline Age $(y)$ & $49(32-75)$ & $34(18-77)$ & $30(16-72)$ & $39(16-85)$ & $60(21-85)^{\star}$ \\
\hline \multicolumn{6}{|l|}{ Disease site } \\
\hline Small bowel & 2 & 14 & 1 & & \\
\hline Ileum & 13 & 43 & 14 & & \\
\hline Ileocaecal \pm colon & 4 & 34 & 11 & & \\
\hline Colon & 3 & 21 & 5 & & \\
\hline Prior resections (\%) & $8(37)$ & $49(44)$ & & & \\
\hline Duration of disease (y) & $8(1-22)$ & $11(0.5-36)$ & & & \\
\hline \multicolumn{6}{|l|}{ Treatment } \\
\hline Prednisolone & 3 & 27 & & & \\
\hline Sulphasalazine & 3 & 9 & & & \\
\hline 5-aminosalicylic acid & 3 & 46 & & & \\
\hline Azothioprine & 0 & 33 & & & \\
\hline
\end{tabular}

Values for age and duration of disease are mean (range).

*Significantly different $(\mathrm{p}<0.0002)$ from patients with Crohn's disease and irritable bowel syndrome. 
study as these conditions may be associated with intestinal inflammation in their own right. ${ }^{24}{ }^{25}$ Also excluded were pregnant women or those at risk of pregnancy and patients with complicated (fistulae, abscesses, or symptomatic intestinal strictures requiring surgery) Crohn's disease.

\section{CROSS SECTIONAL STUDY}

One hundred and sixteen patients with established Crohn's disease (separate from the above), using the same diagnostic and exclusion criteria as above, were recruited for the studies. Forty nine (representing about $25 \%$ of all patients with Crohn's disease in Iceland) were from the Icelandic study centre and 67 were consecutive patients attending King's College Hospital Gastroenterology Outpatients with active disease or attending for routine follow-up.

Patients underwent documentation of demographic details (table 1), physical examination, and assessment of clinical disease activity using the Harvey-Bradsaw scoring system ${ }^{2}$ (48 also had CDAI measured which is more widely used in America than in Europe, but the two correlate significantly ${ }^{2}$ ).

PROSPECTIVE STUDY

We studied 220 consecutive patients, seen between July 1997 and May 1998, referred to a gastroenterology outpatient clinic at King's College Hospital from general practitioners in South London for opinion as to whether they had irritable bowel syndrome or inflammatory bowel disease. None of these patients was included in the above studies. The principal inclusion criteria to this part of the study were that patients had symptoms for at least two months and that at the initial visit to the hospital it was deemed necessary to do an endoscopic and/or intestinal radiological procedure to confirm or exclude inflammatory bowel disease. Therefore, patients with previously diagnosed inflammatory bowel or other intestinal disease were excluded from the study as were those with serious coexisting disease, detailed above in the validation section. Also excluded were patients with intestinal infections (Giardia lamblia, Campylobacter jejuni, Salmonella, Shigella, Yersinia) that were specifically sought for in three faecal samples in patients with diarrhoea at the discretion of the gastroenterologist. Patients with coexisting non-intestinal inflammatory diseases (rheumatoid arthritis, sarcoidosis, infections, etc) that are commonly associated with elevated ESR or CRP were excluded. Also excluded from the study were

Table 2 ROME diagnostic criteria for irritable bowel syndrome

At least three months of continuous or recurrent symptoms of one of the following: Abdominal pain or discomfort

(1) Relieved by defecation

(2) Associated with a change in frequency of stool

(3) Associated with a change in consistency of stool

Two or more of the following, at least on $25 \%$ of occasions or days

(1) Altered stool frequency: more than 3 bowel movements/day or less than 3 bowel movements/week

(2) Altered stool form (lumpy/hard or loose/watery)

(3) Altered stool passage (straining/urgency/feeling of incomplete evacuation)

(4) Passage of mucus

(5) Bloating or feeling of abdominal distension patients in whom ulcerative colitis was seen on sigmoidoscopy and confirmed on biopsy. The reason for excluding these patients is that they do not normally pose a diagnostic problem and a screening test is therefore unlikely to be required or helpful.

Patient demographic details are shown in table 1. All patients had a full medical history taken with a physical examination. Each patient was evaluated by documentation of the ROME criteria (shown in table 2), which has been suggested as a guide for the clinical diagnosis of irritable bowel syndrome, ${ }^{26}{ }^{27}$ and ESR and CRP were measured as part of routine gastrointestinal investigations. All patients had a full blood count, biochemical screening tests (electrolytes, thyroid, liver, and renal profiles), and sigmoidoscopy.

Small intestinal radiology (small bowel follow through $(n=94)$ or enteroclysis $(n=24)$ ) was performed in 118 patients. A barium enema was done in 78 patients. Upper gastrointestinal endoscopy was performed in 57 and colonoscopy in 148 patients. All patients had radiology and/or colonoscopy but the particular investigation and other investigations, such as abdominal ultrasound and CT scans, depended on the patient's symptoms as well as the physician's judgement. Each patient provided a faecal sample for calprotectin estimation within a week of the first visit to the outpatient clinic, which was analysed without knowledge of clinical details. The four gastroenterologists that participated in this part of the study were unaware of the faecal calprotectin result throughout the study.

A diagnosis of Crohn's disease was made on the same basis as that of the other patients with Crohn's disease in this study. ${ }^{21}$ The final diagnosis of the irritable bowel syndrome was made on the basis of no significant haematological or biochemical abnormality and normal radiology or endoscopy with biopsy. Other diseases were diagnosed using generally accepted conventional criteria.

\section{${ }^{111}$ INDIUM LABELLED NEUTROPHIL STUDIES}

Neutrophils were isolated by sedimentation and centrifugation, and labelled with ${ }^{111}$ indium using tropolone as an ionophore, as previously described. ${ }^{28}$ Labelling efficiency averaged 88\% (range $80-97 \%$ ). Abdominal scintigrams were obtained at 1-4 hours and 24 hours to establish disease location. After injection of the cells, individual stool collections were made into plastic containers over a four day period for estimation of ${ }^{111}$ indium activity and calprotectin. Each sample was counted in a high resolution bulk sample counter together with standards for 20-60 seconds, which permits measurement of less than $0.01 \%$ of the injected dose with a counting accuracy of $\pm 4 \%$. The normal range of faecal excretion of ${ }^{111}$ indium over four days (median $0.41 \%, 95 \%$ confidence interval (CI) $0.22-0.81 \%$, with an upper limit (+2SD) of $0.98 \%$ ) had been established previously in 22 healthy subjects (mean age 38 years (range 20-65)). ${ }^{28}$ Assuming that an $11 \mathrm{MBq}$ dose of ${ }^{111}$ indium labelled neutrophils is injected into the patient, the estimated radia- 
tion dose received is $8.5 \mathrm{mSv}$ (effective dose equivalent).

CALPROTECTIN MEASUREMENT

On completion of ${ }^{111}$ indium counting, or on receiving the specimens from subjects in the cross sectional and prospective studies, stools were weighed and a proportion was frozen and stored at $-20^{\circ} \mathrm{C}$. After thawing, $5 \mathrm{~g}$ aliquots were suspended in extraction buffer and calprotectin levels were quantitated using an ELISA method as previously described..$^{18}$

The normal range of faecal calprotectin excretion and concentration was established in 56 healthy subjects ( 31 males, 25 females, mean age 41 years (range 18-77); 21 from Iceland and 35 from King's) during the study. Normal median daily faecal excretion of calprotectin is $0.9 \mathrm{mg}$ with an upper limit (+2SD) of $3 \mathrm{mg}$. Median calprotectin concentrations were $2 \mathrm{mg} / 1(95 \% \mathrm{CI} 2-3 \mathrm{mg} / \mathrm{l})$ with an upper limit (+2SD) of $10 \mathrm{mg} / \mathrm{l}$. The within assay coefficient of variation was $1.2 \%$ and between assay variation $15 \%$.

\section{STATISTICS}

Statistical analysis was performed using Analyse-It medical statistics addition to Microsoft Excel. A "Shapiro-Wilks W" prime test showed that the four day faecal excretion of ${ }^{111}$ indium and faecal calprotectin concentrations from controls were normally distributed while most of the other data were not. Values are therefore presented as median and 95\% confidence intervals (CI). The upper normal limits for the four day faecal excretion of ${ }^{111}$ indium and calprotectin (excretion and concentrations) were defined as mean+2SD. The Mann-Whitney test was used to assess differences in laboratory parameters between groups and Spearman's correlation coefficient was used to assess correlations. Receiver operating characteristics (sensitivity and specificity) were assessed by curve analysis as described by Henderson. ${ }^{29}$

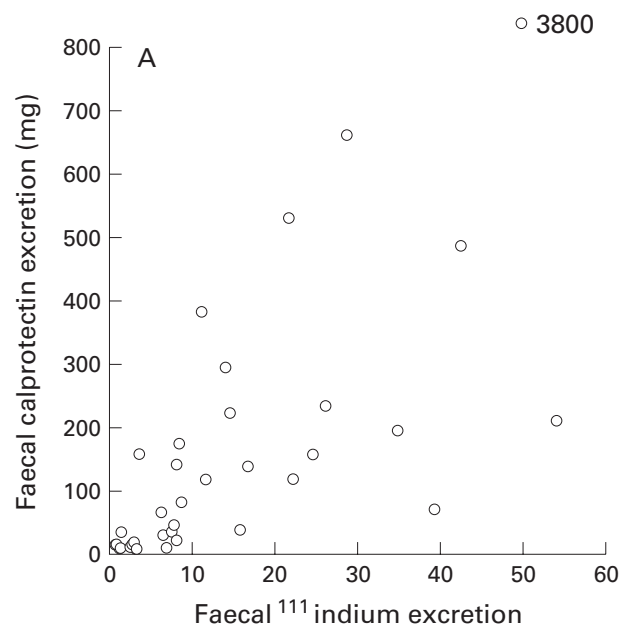

\section{Results}

COMPARISON OF FAECAL EXCRETION AND CONCENTRATION OF CALPROTECTIN WITH FOUR DAY FAECAL EXCRETION OF ${ }^{111}$ INDIUM WHITE CELLS

Figure 1 shows that four day faecal excretion of ${ }^{111}$ indium white cells (median $8.7 \%$; 95\% CI $7-17 \%$; normal $<1.0 \%$ ) from the 22 patients with Crohn's disease tested on 35 occasions correlated significantly $(r=0.80 ; \mathrm{p}<0.001)$ with the cumulative four day faecal excretion of calprotectin (median $101 \mathrm{mg}$; 95\% CI 45-168 $\mathrm{mg}$; normal < $11 \mathrm{mg}$ ). Furthermore, the correlation between daily faecal calprotectin excretion (median 39, 43, 47, and $41 \mathrm{mg}$ on days $1-4$, respectively; normal $<3 \mathrm{mg}$ ) and the four day faecal excretion of ${ }^{111}$ indium was maintained $(r=0.75-0.83 ; \mathrm{p}<0.001)$. The median coefficient of variation between daily faecal excretion of calprotectin in these patients was $29 \%$ (95\% CI $14-79 \%$ ).

The total four day faecal excretion of calprotectin (median $101 \mathrm{mg}$ ) correlated significantly $(r=0.85 ; \mathrm{p}<0.0001)$ with single stool calprotectin concentrations (median $118 \mathrm{mg} / 1 ; 95 \%$ CI $36-175 \mathrm{mg} / \mathrm{l})$. Furthermore, fig 1 shows that the four day faecal excretion of ${ }^{111}$ indium neutrophils and single stool calprotectin concentrations correlated significantly $\quad(r=0.70$; $\mathrm{p}<0.001)$. The median coefficient of variation in calprotectin concentrations in the first morning stool over the four days was $54 \%$ (95\% CI $21 \%-94 \%$ ) with the greatest variability at the lower concentrations.

CROSS SECTIONAL STUDY

There were no significant differences in demographic details between patients in Iceland and the UK. Figure 2 shows that faecal calprotectin concentrations from 116 patients with Crohn's disease (91 mg/l; 95\% CI 59-105 mg/l) differed significantly $(\mathrm{p}<0.0001)$ from controls (2 mg/1; 95\% CI $2-3 \mathrm{mg} / \mathrm{l})$. Only four $(3.4 \%)$ patients with Crohn's disease had calprotectin concentrations within the normal range. These were patients that had undergone multiple intestinal resections.

Figure 1 (A) Four day faecal excretion of ${ }^{111}$ indium labelled white cells (\% dose) plotted against four day faecal excretion $(\mathrm{mg})$ of calprotectin $(r=0.80, p<0.001)$. (B) Four day faecal excretion of ${ }^{111}$ indium white cells plotted against single stool calprotectin concentrations $(\mathrm{mg} / \mathrm{l})(r=0.70, p<0.001)$ in patients with Crohn's disease. 


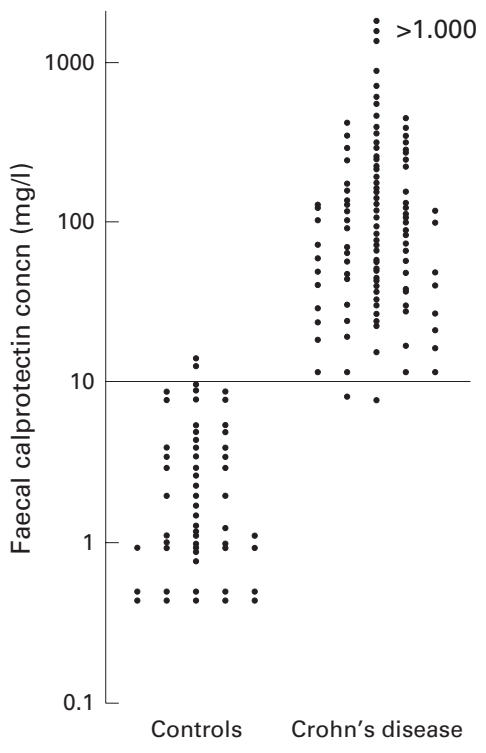

Figure 2 Concentrations of calprotectin (on a logarithmic scale) in faeces in 116 patients with Crohn's disease compared with controls. The horizontal line indicates the upper normal limit (+2SD) for calprotectin concentrations.

CDAI (median 177; 95\% CI 42-311) correlated significantly $(r=0.88, \mathrm{p}<0.0001)$ with the Harvey-Bradshaw activity score, but there was only a weak correlation between these indices $(r=0.46$ and $r=0.42, \mathrm{p}=0.04)$ and faecal calprotectin concentrations in the 48 patients where all three parameters were studied.

The median Harvey-Bradshaw clinical activity score was $5.0(95 \%$ CI $4-15)$ in the 116 patients, which similarly correlated significantly, but weakly $(r=0.37 ; \mathrm{p}<0.05)$, with faecal calprotectin concentrations. Patients $(n=41)$ with clinically active Crohn's disease (Harvey-Bradshaw score of 5 or more or a four point increase from baseline in patients having undergone intestinal resection) had significantly higher $(p<0.001)$ faecal calprotectin concentrations (median $165 \mathrm{mg} / \mathrm{l} ; 95 \%$ CI 96-362 mg/l) than those with quiescent disease (median $87 \mathrm{mg} / \mathrm{l} ; 95 \%$ CI 26-213 mg/l) defined in this way.

PROSPECTIVE STUDY

Of the 220 consecutive subjects referred to the gastroenterology outpatient services, the final diagnosis was Crohn's disease in 31 (eight colonic, 16 ileal or small bowel, and seven ileocaecal), irritable bowel syndrome in 159, and miscellaneous in 30 (microscopic colitis $(n=6)$, diverticulosis/diverticulitis $(n=19)$, and colonic cancer/adenomatous polyps $(n=2$ and $n=3$, respectively)). Demographic details are shown in table 1. Patients in the miscellaneous group were significantly older that the other patients in this study and there were significantly more women in the irritable bowel group than in the other groups.

Figure 3 shows that all patients with Crohn's disease had increased faecal calprotectin concentrations (median $135 \mathrm{mg} / 1$; 95\% CI 105$229 \mathrm{mg} / \mathrm{l}$ ) which differed significantly $(\mathrm{p}<0.0001)$ from normal controls, patients with irritable bowel syndrome $(4 \mathrm{mg} / 1 ; 95 \% \mathrm{CI}$ 3-5 mg/l), and the miscellaneous group (20

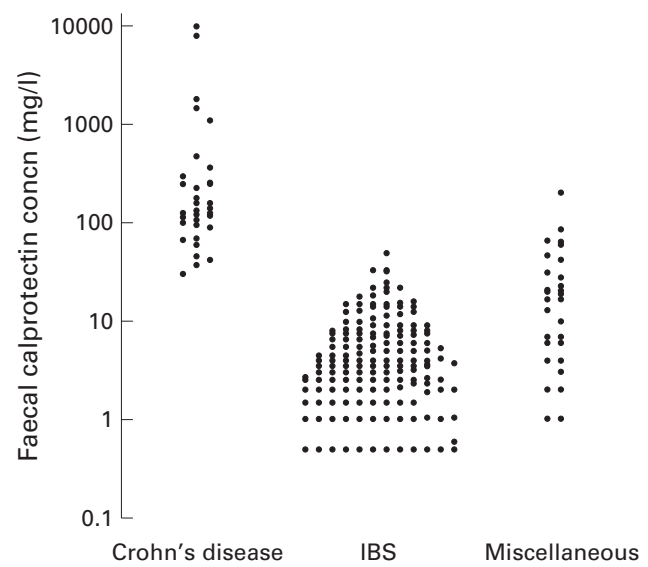

Figure 3 Concentrations of calprotectin (on a logarithmic scale) in faeces in patients subsequently diagnosed as having Crohn's disease, irritable bowel syndrome (IBS), and miscellaneous diseases. The upper normal limit (+2SD) for calprotectin concentrations is $10 \mathrm{mg} / \mathrm{l}$.

$\mathrm{mg} / \mathrm{l} ; 95 \%$ CI $7-28 \mathrm{mg} / \mathrm{l})$. Patients with the irritable bowel syndrome and the miscellaneous group had significantly $(\mathrm{p}=0.0004$ and $\mathrm{p}<0.0001$, respectively) higher faecal calprotectin concentrations than normal controls (2 mg/l; 95\% CI 2-3 mg/l).

Median ESR in patients with Crohn's disease $(23 \mathrm{~mm} / \mathrm{h} ; 95 \%$ CI $10-45 \mathrm{~mm} / \mathrm{h})$ was significantly $(p<0.0001)$ higher than that in patients with the irritable bowel syndrome ( 6 $\mathrm{mm} / \mathrm{h} ; 95 \%$ CI $6-8 \mathrm{~mm} / \mathrm{h})$ but not $(\mathrm{p}=0.24)$ in the miscellaneous group (median $11 \mathrm{mg} / 1 ; 95 \%$ CI $8-44 \mathrm{~mm} / \mathrm{h}$ ). The difference in ESR between patients in the miscellaneous group and those with the irritable bowel syndrome was significant $(p=0.0004)$.

Figure 4 shows CRP values. Median CRP levels in patients with Crohn's disease $(10 \mathrm{mg} / \mathrm{l}$; 95\% CI 3-30 mg/l) were significantly higher than those in patients with the irritable bowel syndrome (3 mg/l; 95\% CI $3-3 \quad \mathrm{mg} / \mathrm{l}$; $\mathrm{p}<0.0001)$, and the miscellaneous group (3 mg/l; 95\% CI 3-7 mg/l; $\mathrm{p}=0.039$ ) but there was no significant difference $(p>0.2)$ between patients with irritable bowel syndrome and the miscellaneous group.

Six $(19 \%)$ of 31 patients with Crohn's disease, $121(76 \%)$ of 159 with the irritable bowel syndrome, and eight $(27 \%)$ of the miscellaneous group fulfilled the ROME criteria for irritable bowel syndrome.

All six patients in the miscellaneous group with microscopic colitis, nine of 19 with diverticulosis/diverticulitis (the study did not allow reliable discrimination between the two), both of the colonic cancer, and two of three patients with adenomatous colonic polyps had increased faecal calprotectin concentrations (above $10 \mathrm{mg} / \mathrm{l}$ ).

The sensitivity and specificity of faecal calprotectin, ESR, and CRP in discriminating between Crohn's disease (analysed separately and together with the miscellaneous group) and irritable bowel syndrome is shown in fig 5 . At a cut off point of $30 \mathrm{mg} / \mathrm{l}$, faecal calprotectin had $100 \%$ sensitivity and $97 \%$ specificity in discriminating between active Crohn's disease and the irritable bowel syndrome. 
Twenty seven patients (17\%) with irritable bowel syndrome had calprotectin concentrations exceeding the upper normal reference value of $10 \mathrm{mg} / \mathrm{l}$. Receiver operating curve

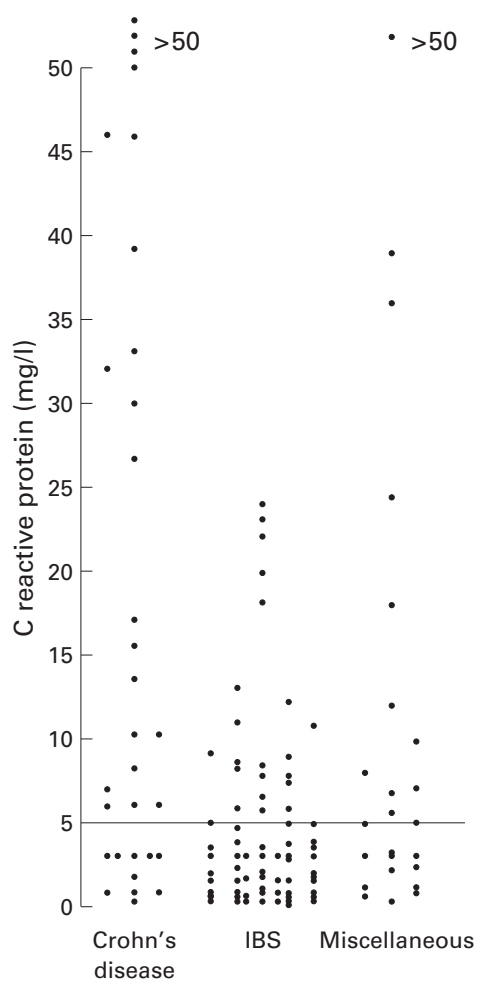

Figure 4 Serum $C$ reactive protein levels in patients subsequently diagnosed as having Crohn's disease, irritable bowel syndrome (IBS), and miscellaneous disease. The upper limit of normal, which had previously been established at the Department of Immunology, King's College Hospital, for $C$ reactive protein is $5 \mathrm{mg} / \mathrm{l}$.

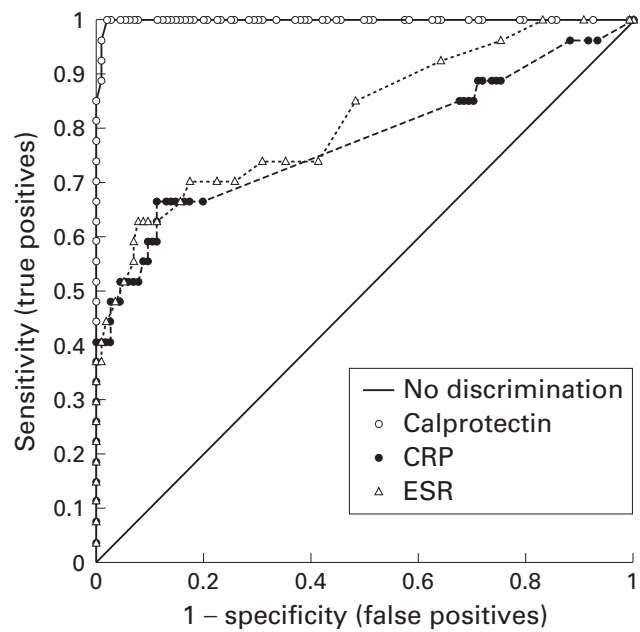

Figure 5 Receiver operating characteristic analysis of the ability of calprotectin, $C$ reactive protein $(C R P)$, and erythrocyte sedimentation rate (ESR) to discriminate between patients with Crohn's disease and the irritable bowel syndrome. The unbroken line ("no discrimination") indicates values that have no discriminatory value. Note that on the vertical axis, the scale is from no (0) to complete (1 or $100 \%$ ) sensitivity. The horizontal axis is a reciprocal scale (1-specificity). The optimum performance of a test is determined either as the highest sum of the specificity and sensitivity or at an acceptable level of sensitivity for the given disease. A cut off value of $30 \mathrm{mg} / \mathrm{l}$ for faecal calprotectin gives $100 \%$ sensitivity and $97 \%$ specificity for discriminating between patients with Crohn's disease and the irritable bowel syndrome. analysis showed that setting an arbitrary upper limit of normal of $15 \mathrm{mg} / \mathrm{l}$, only 13 (8\% false positive rate) patients with the irritable bowel syndrome had increased calprotectin levels.

\section{Discussion}

Abdominal scintigraphy following injection of labelled white cells can be used to indicate the presence, location, and extent of intestinal inflammatory bowel disease ${ }^{8911}$ and measurement of four day faecal excretion of ${ }^{111}$ indium provides a direct quantitative measure of intestinal inflammation. ${ }^{8-11283031}$ The technique is specific for inflammation rather than classic inflammatory bowel disease, as abnormalities are found in various other intestinal inflammatory diseases, ${ }^{24}$ 32-34 including colonic malignancy. ${ }^{35}$ However, it is usually a simple matter to distinguish between these inflammatory conditions and active classical inflammatory bowel disease as the former are associated with a modest 3-8-fold increase in excretion of white cells while there is a $15-50$-fold increase in the latter.

The validity of an inflammatory index, such as faecal calprotectin, is its ability to reflect truly the degree of intestinal inflammation. Without a proven reference or gold standard for this measure in Crohn's disease, we compared the method with that of the ${ }^{111}$ indium white cell technique which is an extensively validated surrogate marker of intestinal inflammation. ${ }^{8-11283031}$ There was a significant correlation between faecal excretion of ${ }^{111}$ indium labelled white cells and calprotectin in patients with Crohn's disease. This correlation was largely maintained when single morning stool calprotectin concentrations were used as opposed to complete one or four day collections. However, this simplification of the test, which is desirable if the technique is to be used as a routine test, is at the cost of reproducibility. The coefficient of variation between daily faecal excretion of calprotectin (29\%) is comparable with that of other faecal markers such as elastase $1(15 \%)$ and chymotrypsin $(30 \%)^{36}$ and is probably due to differences in the uniformity, number, and weight of daily bowel openings as well as the slightly uneven distribution of the markers in faeces. ${ }^{18}$ The coefficient of variation for calprotectin concentrations is somewhat higher (54\%), presumably as this measure is also dependent on stool volume and hydration. This may not be an important drawback of the technique when used in patients with active inflammatory bowel disease as stool volumes are usually increased by less than threefold while calprotectin concentrations are often increased 10 -fold or more. Nevertheless, if intestinal inflammation is low grade or associated with very high volume diarrhoea (acquired immunodeficiency syndrome), a single stool sample may underestimate the severity of the inflammation.

Having shown an acceptable correlation between calprotectin concentrations and four day faecal excretion of ${ }^{11}$ indium white cells, the former was shown to discriminate between normals and $96 \%$ of patients with Crohn's disease in a conventional cross sectional study. 
This is a higher detection rate than is reported with other non-invasive tests apart perhaps from the four day faecal excretion of ${ }^{111}$ indium white cells (reviewed by Hodgson ${ }^{5}$ ). In comparison, other non-invasive procedures for identifying Crohn's disease, such as measurement of intestinal permeability, faecal lysozyme, and non-specific laboratory indices of inflammation (platelet counts, ESR, and CRP), are abnormal in $20-80 \%$ of patients with active disease $\mathrm{s}^{523738}$ and considerably lower in quiescent disease.

There was a significant, albeit weak, correlation between calprotectin concentrations and the two clinical disease activity indexes in the cross sectional study. The lack of a stronger association is not altogether unexpected as the clinical disease activity scores are largely a composite of quantitative subjective symptoms that are affected by non-inflammatory processes such as fibrous strictures, fistulas, previous surgery $(44 \%$ of our patients had undergone intestinal resection), etc. ${ }^{39} 40 \mathrm{By}$ comparison, correlations between faecal excretion of ${ }^{111}$ indium white cells and clinical disease activity indices are usually weak. ${ }^{389} 30314142$ Such findings have suggested that the inflammatory response (excretion of neutrophils) is dependent on the extent of the disease as well as the severity of the inflammation. Furthermore, the cause of symptoms in Crohn's disease is multifactorial. ${ }^{3}$

Regardless of how sensitive the calprotectin technique may be in the detection of patients with previously diagnosed Crohn's disease, its potential use in identifying patients with Crohn's disease and discriminating between them and those with non-inflammatory conditions in a realistic outpatient setting requires study.

However, similar to the ${ }^{111}$ indium white cell technique, the calprotectin method is not specific for inflammatory bowel disease but detects intestinal inflammation due to a variety of causes. ${ }^{19} 4344$ In planning the present study one possibility was to use the method to distinguish between any "intestinal inflammatory condition" and the irritable bowel syndrome in an indiscriminate way. This would have required standardised, inflexible, and complete gastrointestinal investigations (including endoscopy and colonoscopy in all subjects) which was impractical as it would have involved a number of invasive investigations that might not otherwise have been indicated. As a compromise we confined the study to a subgroup of patients where the principal differential diagnosis was between Crohn's disease and the irritable bowel syndrome. This distinction is a familiar problem for general practitioners and this patient group represents a sizeable proportion of gastroenterological referrals ${ }^{45}$; the irritable bowel syndrome being a non-inflammatory intestinal disease affecting $6-20 \%$ of the western population ${ }^{26}$ with symptoms often mimicking those of Crohn's disease. The ROME criteria, a consensus definition proposed as an aid to enable a positive diagnosis of the irritable bowel syndrome, is widely used but in clinical practice the diagnosis of irritable bowel syn- drome remains, by and large, by exclusion of other diseases. ${ }^{26}$ There is, however, a dilemma over how aggressively patients should be investigated before this diagnosis is made and the cost effectiveness of the investigation. ${ }^{45} \mathrm{At}$ present there is no single, simple, and/or specific screening test to discriminate these patients from those with Crohn's disease, many clinicians opting for laboratory screening (ESR, CRP, platelets, full blood count, etc.) before more invasive tests are undertaken. However, a normal "screen" is not conclusive evidence of absence of Crohn's disease and the tests lack specificity for intestinal disease. ${ }^{5}$ Many patients, therefore, undergo extensive and invasive investigations before the diagnosis is made.

To mimic a realistic clinical situation, we excluded (from analysis and inclusion in this study) patients in whom a diagnosis (ulcerative colitis) was made by simple sigmoidoscopic examination and biopsy, even though faecal calprotectin concentrations are almost invariably raised in these patients. ${ }^{20}$ We also excluded patients who had established extraintestinal diseases that are often associated with raised ESR or CRP, thus biasing the results in their favour. Receiver operating curve analysis of faecal calprotectin concentrations under these circumstances showed that a cut off point of $30 \mathrm{mg} / 1$ for calprotectin had $100 \%$ sensitivity and $97 \%$ specificity for discriminating between Crohn's disease and the irritable bowel syndrome. This was significantly better than that obtained with ESR or CRP. Similar prospective studies have not been reported with other faecal markers of intestinal inflammation or with labelled white cells.

Patients in the miscellaneous group had significant pathologies which would be desirable to detect in any screening programme. Including the miscellaneous group with the Crohn's disease group resulted in somewhat lower sensitivity and specificity for faecal calprotectins as just over $50 \%$ of patients with diverticulosis/ diverticulitis had normal results. However, the faecal calprotectin test detected the majority of patients with significant gastrointestinal disease using a cut off point of $13-15 \mathrm{mg} / \mathrm{l}$. Using these cut offs, $23(14 \%)$ and $13(8 \%)$ patients with the irritable bowel syndrome would have undergone invasive investigations, respectively, but this needs to be viewed in the context that the whole group was deemed to require such investigations at the start of the study. Furthermore, although it is desirable to have a method that discriminates effectively between patients with Crohn's disease and the irritable bowel syndrome, it is noticeable that the irritable bowel syndrome group had significantly higher median calprotectin concentrations in stool, with $17 \%$ having values above the upper normal limit $(10 \mathrm{mg} / \mathrm{l})$. This may suggest that a proportion of patients with the irritable bowel syndrome have intestinal disease (such as bacterial or viral infections, small bowel inflammation, etc.) that are not detected by conventional routine investigation. Our somewhat limited work up for intestinal infections, although probably representative of many gastroentero- 
logical practices, is a contentious issue. It is possible that a more extensive investigation (for example, use of electron microscopy for enteric viruses $^{46}$ ) would have identified more pathogens in this patient group.

In summary, faecal excretion and single stool concentrations of calprotectin have been validated against a four day collection in patients with Crohn's disease with satisfactory correlations between the methods. Calprotectin concentrations were elevated in the majority of patients with established Crohn's disease and the method had a high sensitivity and specificity in prospectively discriminating between patients presenting with Crohn's disease and the irritable bowel syndrome. The simplicity of the method, low cost, and sensitivity suggests that it has potential as a routine screening test and may be a useful aid in the differential diagnosis of Crohn's disease and the irritable bowel syndrome.

Dr Tibble was supported by an SE Thames NHS Executive R\&D grant.

1 Best WR, Becktel JM, Singleton JW, et al. Development of a Crohn's disease activity index. Gastroenterology Crohn's disease

2 Harvey RF, Bradshaw JM. A simple index of Crohn's disease activity. Lancet 1980;1:514.

3 Irvine EJ. Finding the right index for IBD. In: Collins SM, Martin F, McLeod RS, et al, eds. Inflammatory bowel disease. Basic research, clinical implications and trends in therapy. Dordrecht: Kluwer Academic Publishers, 1994 191-6.

4 Fagan EA, Dyck RF, Maton PN, et al. Serum levels of C-reactive protein in Crohn's disease and ulcerative colitis. Eur $\mathcal{F}$ Clin Invest 1982;12:351-60.

5 Hodgson HJF. Laboratory markers of inflammatory bowel disease. In: Allan RN, Rhodes JM, Haunauer SB, et al, eds. Inflammatory bowel disease, 3rd edn. New York: Churchill Livingstone, 1997:329-34.

6 Mazlam MZ, Hodgson HJF. Why measure C reactive protein? Gut 1994;35:5-7.

7 Sachar DB, Luppescu NE, Bodian C, et al. Erythrocyte sedimentation as a measure of Crohn's disease activity: opposite trends in ileitis versus colitis. F Clin Gastroenterol opposite trends in

8 Saverymuttu SH, Peters AM, Lavender JP, et al. 111Indium autologous leucocytes in inflammatory bowel Indium autologous leucocyt
disease. Gut 1983;24:293-9

9 Saverymuttu SH, Peters AM, Lavender JP, et al. Quantitative faecal indium-111 labelled leucocyte excretion in assessment of disease activity in Crohn's disease. Gastroenterology 1983;85:1333-9.

10 Saverymuttu SH, Camilleri M, Rees H, et al. Indium-111 granulocyte scanning comparison with colonoscopy, histology and faecal indium-111 excretion in assessing disease extent and activity in colitis. Gastroenterology 1986;90: 1121-8.

11 Roddie ME, Hodgson HJF. Pitfalls in labelled leucocyte scanning. In: Williams CN, ed. Trends in inflammatory bowel disease therapy. Dordrecht: Kluwer Academic Publishers, 1990:121-30.

12 Chadwick VS. Clinical investigation of patients with malabsorption and diarrhoea. In: Bouchier IAD, Allan RN,
Hodgson HJF, et al, eds. Textbook of gastroenterology. Hodgson HJF, et al, eds. Textbook of

13 Braegger CP, Nicholls S, Murch SH, et al. Tumour necrosis factor $\alpha$ in stool as a marker of intestinal inflammation. factor $\alpha$ in stool as a mar.

14 Choudary CP, O'Mahoney S, Brydon G, et al. Gut lavage fluid protein concentrations: Objective measures of disease activity in inflammatory bowel disease. Gastroenterology 1993;104:1064-71

15 Adeyem BO, Hodgson HJF. Faecal elastase reflects disease activity in active ulcerative colitis. Scand 7 Gastroenterol 1992;27:139-42.

16 Uchida K, Matsuse R, Tomita S, et al. Immunochemical detection of human lactoferrin in faeces as a new marker of inflammatory gastrointestinal disorders and colon cancer. Clin Biochem 1994;27:259-64.

17 Guerrant RL, Araujo V, Soares E, et al. Measurement of fecal lactoferrin as a marker of fecal leukocytes. 7 Clin Microbiol 1992;30:1238-42.
18 Roseth AG, Fagerhol MK, Aadland E, et al. Assessment of the neutrophil dominating calprotectin in feces. A methodologic study. Scand $\mathcal{f}$ Gastroenterol 1992;27:793-8.

19 Roseth AG, Kristinsson J, Fagerhol MK, et al. Faecal calprotectin: A novel test for the diagnosis of colorectal cancer? Scand f Gastroenterol 1993;28:1073-6.

20 Roseth AG, Aadland E, Jahnsen J, et al. Assessment of disease activity in ulcerative colitis by faecal calprotectin, a novel granulocyte marker protein. Digestion 1997;58:176 80 .

21 Malchow H, Ewe K, Brandes JW, et al. European cooperative Crohn's disease study (ECCDS): results of drug treatment. Gastroenterology 1984;86:249-66.

22 Best WR, Becktel JM. The Crohn's disease activity as a clinical instrument. In: Pena A, Weterman IT, Booth CC, et al, eds. Recent advances in Crohn's disease. The Hague: Martimus Nijhoff, 1981:7-12.

23 Best WR, Becktel JM, Singleton JW. Rederived values of the eight coefficients of the Crohn's disease activity index (CDAI). Gastroenterology 1979;77:843-6.

24 Bjarnason I, Hayllar J, Macpherson AJ, et al. Side effects of nonsteroidal anti-inflammatory drugs on the small and large intestine. Gastroenterology 1993;104:1832-47.

25 Bjarnason I, Macpherson AJM, Hollander D. Intestinal permeability: An overview. Gastroenterology 1995;108: 1566-81.

26 Drossman DA, Whitehead WE, Camilleri M. Irritable bowel syndrome: A technical review for practice guideline development. Gastroenterology 1997;112:2120-37.

27 Lynn RB, Friedman LS. Irritable bowel syndrome. N Engl f Med 1993;329:1940-5.

28 Teahon K, Smethurst P, Levi AJ, et al. The effect of elemental diet on intestinal permeability and inflammation in Crohn's disease. Gastroenterology 1991;101:84-9.

29 Henderson AR. Assessing test accuracy on its clinical consequence: a primer for receiver operating characteristics curve analysis. Ann Clin Biochem 1993;30:521-39.

30 Saverymuttu SH. Clinical remission in Crohn's diseaseAssessment using faecal indium-111 granulocyte excretion. Digestion 1986;33:74-9.

31 Teahon K, Smethurst P, Macpherson AJ, et al. Intestinal permeability in Crohn's disease and its relation to disease activity and relapse following treatment with elemental diet. Eur $\mathcal{7}$ Gastroenterol Hepatol 1993;5:79-84.

32 Teahon K, Webster AD, Price AB, et al. Studies of gastrointestinal structure and function in patients with primary hypogammaglobulinaemia. Gut 1994;35:1244-9.

33 Bjarnason I, Sharpstone D, Francis N, et al. Intestinal inflammation, ileal structure and function in HIV. AIDS 1996;10:1385-91

34 Kardossis T, Joseph AEA, Gane JN, et al. Fecal leucocytosis. Indium-111 labelled autologous polymorphonuclear leucocyte abdominal scanning, and quantitative fecal indium111 excretion in acute gastroenteritis and enteropathogen carriage. Dig Dis Sci 1988;33:1383-90.

35 Saverymuttu SH, Maltby P, Batman P, et al. False positive localisation of indium-111 granulocytes in colonic carcilocalisation of indium-111 granulo
noma. Br F Radiol 1986;59:773-7.

36 Loser C, Mollgaard A, Folsch UR. Faecal elastase 1: a novel, highly sensitive, and specific tubeless pancreatic function test. Gut 1996;39:580-6.

37 Tromm A, Tromm CD, Huppe D, et al. Evaluation of different laboratory tests and activity indices reflecting the inflammatory activity of Crohn's disease. Scand f Gastroenterol 1992;27:774-8.

38 van der Sluys Veer A, Brouwer J, Biedmond I, et al. Fecal lysozyme in assessment of disease activity in inflammatory bowel disease. Dig Dis Sci 1998;43:590-5.

39 Spence DT, Mayberry JF. Clinical indices in inflammatory Spence DT, Mayberry JF. Clinical indices in inflammatory
bowel disease. In: Allan RN, Rhodes JM, Haunauer SB, et bowel disease. In: Allan RN, Rhodes JM, Haunauer SB, et
al, eds. Inflammatory bowel disease, 3rd edn. New York: al, eds. Inflammatory bowel disease,
Churchill Livingstone, 1997:335-41.

40 Brooke BN. Index of Crohn's disease activity. Lancet 1980;i: 711 .

41 Crama-Bohbouth G, Pena AS, Biemond I, et al. Are activity indices helpful in assessing active intestinal inflammation in Crohn's disease? Gut 1989;30:1236-40.

42 Teahon $\mathrm{K}$, Pearson $\mathrm{M}$, Smith $\mathrm{T}$, et al. Alterations in nutritional status and disease activity during treatment of Crohn's disease with elemental diet. Scand $\mathcal{f}$ Gastroenterol 1995;30:54-60.

43 Meling TR, Aabakken L, Roseth A, et al. Faecal calprotectin shedding after short-term treatment with non-steroidal anti-inflam $339-44$.

44 Tibble J, Sigthorsson G, Foster R, et al. NSAID enteropathy: A new simple diagnostic test. Gut 1998; 42(suppl 1):A36.

45 Harris MS. Irritable bowel syndrome. A cost effective approach for primary care physicians. Postgrad Med 1997;101:215-26.

46 Grohmann GS, Glass RI, Pereira HG, et al. Enteric viruses and diarrhoea in HIV-infected patients. $N$ Engl $f$ Med 1993;329:14-20. 